\title{
PREVALENT ISSUES IN BIM-BASED CONSTRUCTION PROJECTS
}

\author{
Rahimi A. Rahman ${ }^{1}$ and Steven K. Ayer ${ }^{2}$
}

\begin{abstract}
Adopting Building Information Modelling (BIM) can result in various potential benefits. Previous research has identified challenges related to implementing BIM in construction projects. However, such studies may not demonstrate the regularity of those challenges in different construction projects. Understanding the prevalent challenges in BIM-based construction projects can assist in educating students on the prospective challenges in their upcoming projects. This research analyses issue logs from an electrical contractor to answer the following questions: (1) What are the prevalent issues that occur in BIM-based construction projects? (2) What are the dominant causes of issues in BIM-based construction projects? Both qualitative and quantitative approaches are used to analyse the logs. The qualitative analysis involves performing thematic analysis to identify the themes of issues and causes of issues. Conversely, the quantitative analysis involves grouping and counting the logs using those themes to determine the prevalent issues and dominant cause of issues. The results suggest that the common causes of issues in the projects are people and process rather than technology. This research adds to the body of knowledge by determining the prevalent issues of BIM-based construction projects as well as the dominant causes of issues by analysing issue logs across different construction projects.
\end{abstract}

Keywords: Building Information Modelling (BIM), construction projects, issues and challenges, issue logs, thematic analysis.

\section{INTRODUCTION}

The architecture, engineering, and construction (AEC) industries pursue various methods to decrease project cost, increase productivity and quality, and reduce project delivery time. Building Information Modelling (BIM) can help to address these goals by saving time and cost (Bryde et al 2013). While BIM offers potential benefits, other research has suggested that the way it is implemented can impact the outcomes. Specifically, challenges related to people, process, and technology can all influence the observable impact of BIM (Arayici et al 2011).

Research over the last decade indicates the different challenges of implementing BIM in construction projects (Gu and London; 2010; Azhar 2011; Arayici et al 2011; Hamdi and Leite 2013). However, it is not clear how often these various issues arise from project to project. Comprehending the prevalence of issues commonly observed on BIM-based construction projects may enable practitioners to plan for how they implement BIM. Similarly, this understanding may enable educators to strategically plan what they aim to teach students who will go on to careers in the AEC industry.

1 Graduate Research Associate, School of Sustainable Engineering and the Built Environment, Arizona State University, Arizona, USA, r.rahimi@asu.edu

2 Assistant Professor, School of Sustainable Engineering and the Built Environment, Arizona State University, Arizona, USA, steven.ayer@asu.edu 
This research analyses problem log issues from an electrical construction company to answer the following questions: (1) What are the prevalent issues that occur in BIMbased construction projects? (2) What are the dominant causes of issues in BIM-based construction projects? To answer these questions, the authors analysed issue logs from an electrical contractor in the Southwest United States. The issue logs contained data from fifty-seven BIM projects. This research first identifies the themes of issues and causes of issues from the logs. Then the authors grouped the issue logs using these themes. Finally, the frequency of these issues is compared to determine the prevalent issues and the dominant causes of issues.

\section{BACKGROUND}

Although the challenges of adopting BIM in construction projects have been identified through various methods, the prevalent issues and dominant causes in different BIMbased construction projects have not been determined. Past research acknowledged the technical and managerial challenges of implementing BIM through reviewing the available literature (Azhar 2011); and the challenge of having unaligned stakeholders through expert interviews and questionnaire surveys (Hamdi and Leite 2013). Also, challenges of managing change were recognized after analysing the benefits of construction projects by using secondary data of different case studies from academic journals (Bryde et al 2013). Different expectations of BIM across the AEC discipline were identified by analysing the readiness of the construction industry to adopt BIM through focus group interviews ( $\mathrm{Gu}$ and London 2010). In addition to identifying those challenges, past research has determined the most influential risk factor by analysing questionnaire surveys (Chien et al 2014), and the critical success factors for companies in their first wave of adopting BIM through face-to-face interviews (Won et al 2013). These prior efforts have effectively identified the different challenges, critical success factors, and the risk factor that can impact the success of adopting BIM.

In addition to studies that explored BIM challenges through broadly disseminated survey and interview approaches, past research has also identified specific challenges in BIM projects through case studies. The case studies include analysing the BIM adoption process of four projects in two mid-sized engineering firms for two years (Kaner et al 2008), and two healthcare projects for two years (Manning and Messner 2008). To analyse the collaboration aspect of BIM, another study analysed project field notes, formal and informal interviews, and other project information of two case studies (Dossick and Neff 2010). Another case study assessed the relevant BIM technologies in demonstrating the efficiency gains of lean architectural practice from a two-year project (Arayici et al 2011). These researchers have identified various challenges of implementing BIM in construction projects. To advance the comprehension of the challenges in BIM-based construction projects, this research focuses on analysing issue logs of multiple projects with BIM from a specialty contractor. This analysis provides a method for determining the prevalent issues and the dominant causes of issues.

\section{Methodology}

The data collection involves acquiring data from an electrical contractor in the form of issue logs. Both qualitative and quantitative approaches are used to analyse the collected data. The following subsections discuss the methods of collecting and analysing the issue logs. 


\subsection{Data Collection}

Issue logs can be considered as one of the project documents that may emerge from the activity of managing issues between different stakeholders in projects (PMI 2013). The data collection involves acquiring issue logs from the office of a large electrical contractor in Phoenix, AZ. This office manages all the BIM activities of the company. Therefore, although the data came from a single location, it includes issues from projects located throughout the United States. The contractor anonymized the specific project owner names, project names, and individual names before distributing the issue logs to the authors. Other than these anonymizations, the issue logs did not go through any other modifications or preparations for this research.

In total, the data collection consists of 828 issues logs from fifty-seven BIM-based construction projects that occurred from June 1, 2014, to May 31, 2016. The issue logs include both ongoing and past issues from various BIM projects of the contractor. The types of information in the data includes project number, date of logging, the issue, solutions to the issue logs, and additional notes to the issue logs. This research focuses on analysing issue logs that illustrate issues that arise in the projects. In this research, "issues" are defined as problem log line items that illustrate a project occurrence that would require some type of fix or remediation. Therefore, the authors removed issue log line items that reflect reporting of information such as "rework for basement level 2 is now finished and has been submitted." Conversely, all types of projects are included in the analysis.

\subsection{Data Analysis: Identifying the Issues and Causes of Issues}

The qualitative analysis of this research involves performing thematic analysis on the issue logs. This analysis identifies the themes of issues before consolidating them into core categories. Other research has also used thematic analysis to analyse issue logs in order to determine the source of organization misalignments and their influence on the choices of resolving those misalignments (Soh and Sia 2004), and explore the successes and challenges in the implementation of care pathways in one of the National Health Service provided in Leicestershire, United Kingdom (Wood et al 2014).

The authors perform the thematic analysis as outlined by Boyatzis (1998). The method involves two phases: (1) identification; and (2) consolidation. The identification phase involves iterative readings of the issues, solutions, and additional notes to identify the appropriate themes. This phase identified forty-four initial issues. The consolidation phase combines repetitive themes and interrelated issues from the initial list. For example, this phase combined "mistake in modelling," "misinterpret information," and "misclick in the model" into the same category of "human error." The authors determined the eleven categories as the themes of issues and the four core categories as the causes of issues. The four causes of issues are "people," "process," "technology," and "others." This research does not present the results for "others" that consist of "differing site conditions" and "unexpected weather" as the issues are non-actionable.

\subsection{Data Analysis: Determining the Prevalent Issues}

The quantitative analysis of this research involves grouping and counting the issue logs. This analysis is performed to determine the prevalent issues in BIM-based construction projects. Those logs are grouped using the nine themes of issues from the people, process, and technology core categories. 
The grouping process is followed by counting the number of issue logs that are grouped in each theme of issues. This step computes the frequency of those themes of issues. Finally, the means and standard deviations of each theme are computed from those frequencies and the total number of projects. For example, "transfers of information" has 144 issues from the 57 projects. Therefore, the mean is 2.53 after dividing those 144 issues to the 57 projects. Conversely, the standard deviation is the variation of the 144 issues in the 57 projects.

Finally, the prevalent issues are determined from the means and standard deviations. First, those with the highest means are considered as the prevalent issues. Additionally, this research also considers those with means that are not significantly different from the highest means as the prevalent issues. The authors performed the Least Significant Difference (LSD) test to identify those means that are not significantly different. This test computes the LSD between means to identify those with significant difference larger than the LSD (Williams and Abdi 2010).

\section{RESUlts}

Figure 1 shows the themes of issues and the underlying causes of issues, as identified through the thematic analysis. The causes of issues are (1) process; (2) people; and (3) technology. People is the underlying cause of "human error," "miscommunication," "insufficient training or experience," and "individual personalities;" while process is the cause of issues for "transfers of information," "changes," and "unclear process." Finally, technology is the underlying cause for "inefficient," and "breakdowns." From the thematic analysis on the issue logs, this research identified nine themes of issues and three causes of issues in BIM-based construction projects.

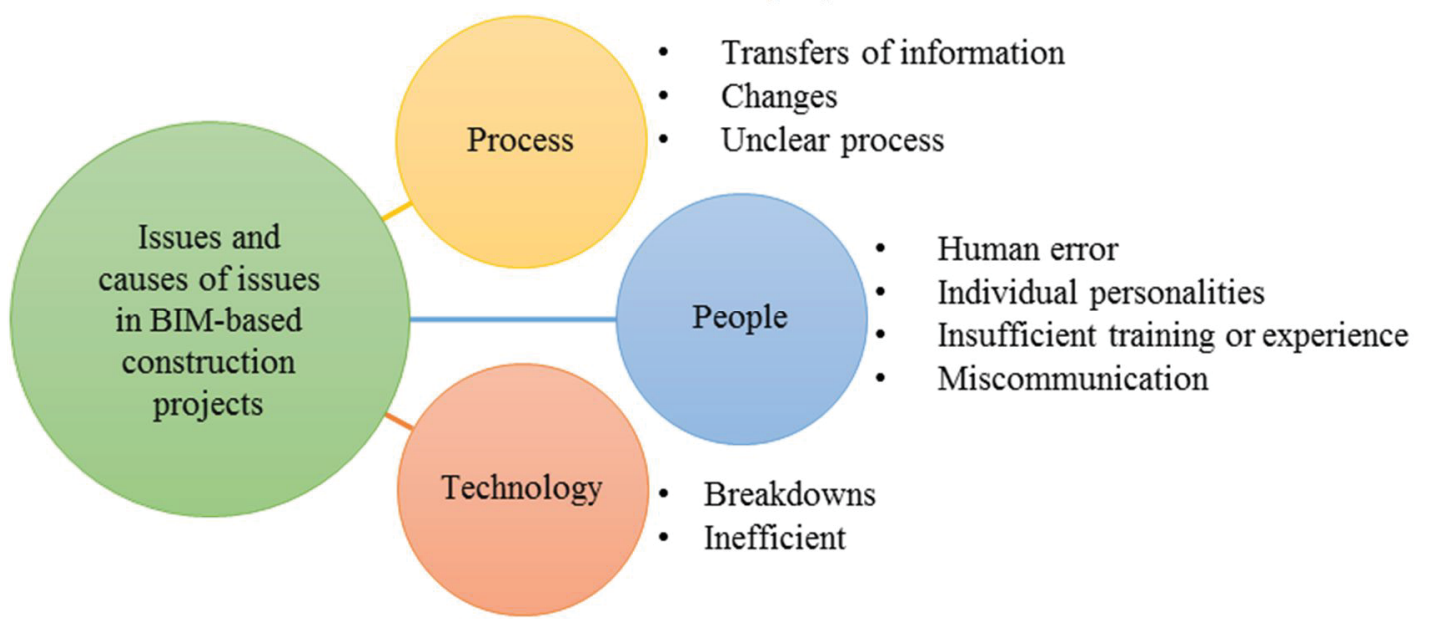

Figure 1: Issues and causes of issues in BIM-based construction projects

\subsection{Prevalent Issues}

Table 1 shows the frequency, mean and standard deviation of issues in each theme. "Transfers of information" has the highest frequency compared to other issues. "Changes," "human error," "individual personalities," and "breakdowns" are the issues that have no significant difference with "transfers of information" at $p<0.05$ from the Least Significant Difference test. These results illustrate the prevalent issues in BIMbased construction projects. The following sub-sections present the definition, scope, and examples of those issues. 
Table 1: Frequency, mean, and standard deviation of issues in each theme.

\begin{tabular}{ccccccc}
\hline $\begin{array}{l}\text { Cause of } \\
\text { issue }\end{array}$ & $\mathbf{n}$ & $\begin{array}{c}\text { Percentage from } \\
\mathbf{N}, \mathbf{N}=\mathbf{6 8 4}\end{array}$ & Issue & $\mathbf{n}$ & Mean & $\begin{array}{c}\text { Standard } \\
\text { deviation }\end{array}$ \\
\hline Process & 324 & $47.37 \%$ & Transfers of information & 144 & $2.53^{\circ}$ & 6.78 \\
& & & Changes & 116 & $2.04^{\circ}$ & 4.75 \\
& & & Unclear process & 64 & 1.12 & 2.32 \\
\hline People & 271 & \multirow{2}{*}{$39.62 \%$} & Human error & 110 & $1.93^{\circ}$ & 3.32 \\
& & & Individual personalities & 103 & $1.81^{\circ}$ & 3.72 \\
& & & Insufficient training or & 39 & 0.68 & 1.26 \\
& & & experience & & & \\
& & & Miscommunication & 19 & 0.33 & 0.81 \\
\hline Technology & 89 & $13.01 \%$ & Breakdowns & 74 & $1.30^{\circ}$ & 2.13 \\
& & & Inefficient & 15 & 0.26 & 0.64 \\
\hline
\end{tabular}

"Issues that have no significant difference with "transfers of information" at $p<$ 0.05 from the Least Significant Difference test.

\subsubsection{Transfers of Information $(n=144)$}

"Transfers of information" refers to instances on projects when individuals needed to exchange some type of information. The scope of this issue includes awaiting information from another party, not receiving updates from another party, contradicting information between different parties, and other party providing information at the last minute. An example from the issue logs: "Never received a change order for electrical equipment. Received today, had an effect on the electrical room, the layout of equipment, underground conduit, multiple views, and sheet dimensioning."

\subsubsection{Changes $(\mathrm{n}=116)$}

"Changes" stands for complications that are caused by any acts or instances that result in something different at any time during the project. Design changes, change in work scope, and change in work schedule are all included in this issue. Common design changes in construction projects such as "architectural design change caused the electrical layout to change," and other type of changes such as "received detailing input that changes the way we've done and agreed to do the detailing and modeling. This changes at this point are going to create a large amount of rework," are some of the issue logs.

\subsubsection{Human Error $(\mathrm{n}=110)$}

This research defines "human error" as something that has been done that was not the intention of an individual. The authors consider providing incorrect or incomplete information, misinterpreting information, making mistakes during modelling, and "misclicks" in the model as the scope of human error. For example, this research identified "back in February, we sent a request asking for lighting layout (LD) for level 4 to 38. We were told that level 3 can be copied up to the tower. Once we hit level 34, there are larger units and the door layout is different. (Issue is known on June)" as providing incorrect information, which is one of the initial codes of human error 


\subsubsection{Individual Personalities $(\mathrm{n}=103)$}

"Individual personalities" refers to difficulties that are either a combination of individual characteristics and qualities or one of those elements respectively. However, this issue excludes "human error." The scope of this issue involves not following protocol, not attending meetings, not responding to emails and missing datelines. An example includes "those currently in the project have ignored the recommendation of prioritizing tasks or actions. Those modeling the production model are updating model after field installation to match what is installed."

\subsubsection{Breakdowns $(\mathrm{n}=74)$}

"Breakdowns" in this research stands for technological failure. The scope of this issue includes failures of software, hardware, server, model, file, and the internet. An example from the issue logs is "seems to be having issues with software after a computer update this morning."

\subsection{Underlying Causes of Prevalent Issues}

Table 1 shows the underlying causes of the prevalent issues. The results suggest that process is the underlying cause for "transfers of information" and "changes," while people is the underlying cause of "human error" and "individual personalities." Lastly, technology is the underlying cause of "breakdowns." These results illustrate that the dominant causes of prevalent issues are people and process.

\subsection{Underlying Causes of Overall Issues}

In addition to the underlying causes of the prevalent issues, Table 1 also shows the underlying causes of all other issues. From the results, process cause $47.37 \%$ of the issues, people cause $39.62 \%$ of the issues, and technology cause $13.01 \%$ of the issues. These numbers illustrate that process and people are responsible for a higher percentage of issues than technology. Additionally, three-quarters of the issues are caused by people and process while technology causes less than one-seventh of the issues in those projects. In other words, people and process are the dominant causes of both overall issues and prevalent issues in the BIM- based construction projects in this research.

\section{DISCUSSION}

The results illustrate that the prevalent issues in BIM-based construction projects from the issue logs are transfers of information, changes, human error, individual personalities, and breakdowns. Additionally, the common causes of both the overall issues and prevalent issues in such projects are people and process rather than technology. However, past research suggests that most challenges related to implementing BIM have been focused on software and hardware issues (Bryde et al 2013). Past research also suggests that the construction engineering and management curriculum should concentrate on practice based topics rather than the engineering and technical aspects of BIM (Becerik-Gerber et al 2011). Additionally, preference should be given to understanding the principles of BIM rather than mastering the software (Wang and Leite 2014). In other words, although most of the issues in BIM-based construction projects are related to people and process, past research suggests that the majority of the BIM courses are technology-related.

This research analyses issue logs to determine the prevalent issues and the dominant causes of issues in BIM-based construction projects. To ensure the issue logs are 
recorded in a naturalistic environment without any influence from the authors, the data collection involves acquiring past issue logs from an electrical contractor. The contractor did not modify or prepare the issue logs in any way for the researchers, besides anonymizing identifiable information during the data turnover. Additionally, the authors did not discuss the findings with the contractor to avoid any influence from the contractor. The research design can be replicated by performing the same analysis on other issue logs. The authors acknowledge that the data analysis process can theoretically introduce some subjective bias, specifically between the themes of issues in the people and process core categories. While there may be some slight debate over the exact percentages of sources of issues, this work seems to clearly show that the common causes of issues in BIM-based construction projects are people or process, and not technology.

\section{CONCLUSION}

This research analyses issue logs from an electrical subcontractor to determine the prevalent issues and dominant causes of issues in BIM-based construction projects. The authors first performed thematic analysis on the issue logs of fifty-seven construction projects that implemented BIM to identify the themes of issues and causes of issues. Then, the authors grouped the issues logs using those themes to determine the prevalent issues and dominant causes of issues. The results show that the prevalent issues are transfers of information, changes, human error, individual personalities, and breakdowns. Then, people and process are the dominant causes of issues for both the prevalent issues and the overall issues.

Although the common causes of issues in BIM-based construction projects are people and process, past research suggests that there has been a greater focus on the technology when associating BIM and construction projects. Based on these findings, stakeholders and educators in the AEC industry should also consider preparing individuals with the competencies to face people- and process-related issues. Future work will aim to identify appropriate pedagogical strategies to educate students on how to avoid and deal with them. This research contributes to the body of knowledge by determining the prevalent issues and dominant causes of issues in the adoption of BIM in construction projects by analysing issue logs across different construction projects.

\section{ACKNOWLEDGMENTS}

The authors would like to thank Mr. Fred Meeske from Rosendin Electric for providing the data and support to conduct this research project. Any expression in this material are those of the authors and do not necessarily reflect the views of Rosendin Electric or Arizona State University.

\section{REFERENCES}

Arayici, Y., Coates, P., Koskela, L., Kagioglou, M., Usher, C. and O'reilly, K., (2011). Technology Adoption in the BIM Implementation for Lean Architectural Practice. Automation in Construction, 20(2), pp.189-195.

Azhar, S. (2011). Building Information Modeling (BIM): Trends, Benefits, Risks, and Challenges for the AEC Industry. Leadership and Management in Engineering, 11(3), pp.241-252. 
Becerik-Gerber, B., Gerber, D.J. and Ku, K. (2011). The Pace of Technological Innovation in Architecture, Engineering, and Construction Education: Integrating Recent Trends into the Curricula. Journal of Information Technology in Construction, 16(2011), pp.411-432.

Boyatzis, R.E. (1998). Transforming qualitative information: Thematic analysis and code development. Sage.

Bryde, D., Broquetas, M. and Volm, J.M. (2013). The Project Benefits of Building Information Modelling (BIM). International Journal of Project Management, 31(7), pp.971-980.

Chien, K.F., Wu, Z.H. and Huang, S.C. (2014). Identifying and Assessing Critical Risk Factors for BIM Projects: Empirical Study. Automation in Construction, 45, pp.1-15.

Dossick, C.S. and Neff, G., (2010). Organizational Divisions in BIM-Enabled Commercial Construction. Journal of Construction Engineering and Management, 136(4), pp.459467.

Gu, N. and London, K. (2010). Understanding and Facilitating BIM Adoption in the AEC Industry. Automation in Construction, 19(8), pp.988-999.

Hamdi, O. and Leite, F. (2013). Conflicting Side of Building Information Modeling Implementation in the Construction Industry. Journal of Legal Affairs and Dispute Resolution in Engineering and Construction, 6(3), p.03013004.

Kaner, I., Sacks, R., Kassian, W. and Quitt, T. (2008). Case Studies of BIM Adoption for Precast Concrete Design by Mid-Sized Structural Engineering Firms. Journal of Information Technology in Construction, 13 (3) (2008), pp. 303-323.

Manning, R. and Messner, J. (2008). Case Studies in BIM Implementation for Programming of Healthcare Facilities. Journal of Information Technology in Construction, 13 (2008), pp. 446-457.

PMI (2013). Guide to the Project Management Body of Knowledge (5th Edition). Project Management Institute, Inc. (PMI).

Soh, C. and Sia, S.K. (2004). An Institutional Perspective on Sources of ERP PackageOrganisation Misalignments. The Journal of Strategic Information Systems, 13(4), pp.375-397.

Wang, L. and Leite, F. (2014). Process-Oriented Approach of Teaching Building Information Modeling in Construction Management. Journal of Professional Issues in Engineering Education and Practice, 140(4), p.04014004.

Williams, L.J. and Abdi, H. (2010). Fisher's least significant difference (LSD) test. Encyclopedia of research design, pp.1-6.

Won, J., Lee, G., Dossick, C. and Messner, J. (2013). Where to Focus for Successful Adoption of Building Information Modeling within Organization. Journal of Construction Engineering and Management, 139(11), p.04013014.

Wood, S., Gangadharan, S., Tyrer, F., Gumber, R., Devapriam, J., Hiremath, A. and Bhaumik, S. (2014). Successes and Challenges in the Implementation of Care Pathways in an Intellectual Disability Service: Health Professionals' Experiences. Journal of Policy and Practice in Intellectual Disabilities, 11(1), pp.1-7. 